Fichte sobre a estrutura do Eu. Uma investigação crítica acerca da interpretação de Dieter Henrich do "Ensaio de uma nova exposição da doutrina da ciência", de Fichte

\title{
Stefan Lang
}

\section{OpenEdition}

\section{Journals}

Edição electrónica

URL: https://journals.openedition.org/ref/1851

DOI: $10.4000 /$ ref.1851

ISSN: 2258-014X

\section{Editora}

EuroPhilosophie Editions

\section{Refêrencia eletrónica}

Stefan Lang, «Fichte sobre a estrutura do Eu. Uma investigação crítica acerca da interpretação de Dieter Henrich do "Ensaio de uma nova exposição da doutrina da ciência", de Fichte», Revista de Estud(i)os sobre Fichte [Online], 23 | 2021, posto online no dia 01 dezembro 2021, consultado o 05 março 2022. URL: http://journals.openedition.org/ref/1851 ; DOI: https://doi.org/10.4000/ref.1851

Este documento foi criado de forma automática no dia 5 março 2022

(c) EuroPhilosophie 


\title{
Fichte sobre a estrutura do Eu. Uma investigação crítica acerca da interpretação de Dieter Henrich do "Ensaio de uma nova exposição da doutrina da ciência", de Fichte
}

\author{
Stefan Lang
}

\section{Introdução}

O artigo de Dieter Henrich "O insight originário de Fichte" é tido entre as investigações mais significativas e mais influentes da subjetividade humana e da filosofia de Johann Gottlieb Fichte, que foram publicadas nas últimas décadas. ${ }^{1}$ No centro do artigo de Henrich está a análise da estrutura do $e u{ }^{2}$ No âmbito da investigação de Henrich, a tarefa que uma análise da estrutura do eu deve solucionar, do ponto de vista do conteúdo, consiste em explicar a produção e a constituição do eu. ${ }^{3}$ Uma explicação da produção do eu expõe o modo como o eu é produzido - por exemplo, através de uma investigação da atividade espontânea do espírito humano. ${ }^{4} \mathrm{Em}$ contrapartida, uma explicação da constituição revela em que consiste o eu, isto é, quais componentes são componentes necessários do eu e em quais relações necessárias esses componentes estão entre si. Por exemplo, conforme a visão de alguns filósofos analíticos, um estado mental consciente (estado de consciência/state-consciousness) - para falar de modo mais simplificado consiste no fato de que um estado mental, ou seja, um pensamento, representa atualmente de uma maneira não-inferencial um outro estado mental, por exemplo, um estado de percepção visual, de modo que o estado mental representado é um estado mental consciente. ${ }^{5}$ Segundo Henrich, o eu ou o sujeito ${ }^{6}$ se caracteriza particularmente por ter autoconsciência. Sua análise da estrutura do eu, por isso, inclui uma investigação da constituição e da produção da autoconsciência. Henrich investiga com isso, entre outras coisas, a pergunta de como o eu obtém o saber de ter consciência de si 
mesmo. ${ }^{7}$ Assim, em sua análise da estrutura do eu, Henrich trata de temas centrais da teoria do eu e da autoconsciência de Johann Gottlieb Fichte. A explicação da constituição bem como da produção do eu e de sua autoconsciência formam o foco principal, sobretudo, das primeiras exposições fichteanas da Doutrina da Ciência. ${ }^{8}$ Conforme Henrich, Fichte realizou nesse domínio temático algo definitivamente revolucionário. ${ }^{9}$ Daí Henrich desenvolver n' "O insight originário de Fichte" suas reflexões sistemáticas sobre a estrutura do eu, entre outras coisas, no contexto de uma explicação que valoriza as interpretações fichteanas do eu e da autoconsciência nas diferentes exposições da Doutrina da Ciência. Não obstante, as explicações fichteanas do eu e da autoconsciência apresentam, segundo Henrich, graves déficits. O objetivo deste presente artigo consiste, primeiro, em expor a interpretação de Henrich acerca do ponto de vista fichteano no "Ensaio de uma nova exposição da doutrina da ciência" e suas críticas a Fichte..$^{10}$ Ele consiste, em segundo lugar, no desenvolvimento de uma interpretação alternativa da posição de Fichte, e por fim, em terceiro lugar, na confirmação de que, conforme a diretriz desse modo alternativo de leitura, a crítica de Henrich a Fichte pode ser rejeitada como infundada.

Na primeira seção dessa investigação, será discutida a interpretação de Henrich acerca do ponto de vista de Fichte no "Ensaio de uma nova exposição da doutrina da ciência" e investigada sua crítica a Fichte. Na segunda seção, será apresentado, com o recurso a reflexões de Christian Klotz, um modo alternativo de leitura do "Ensaio de uma nova exposição da doutrina da ciência". ${ }^{11}$ Esse modo alternativo será completado na terceira seção por meio de um modelo performativo de explicação. Nessa seção será mostrado, além disso, que a crítica de Henrich a Fichte pode ser rejeitada como não justificada conforme a diretriz dessa interpretação alternativa.

\section{Interpretação epistemológica de Henrich}

Segundo Henrich, a fórmula com a qual Fichte caracteriza a estrutura do eu no "Ensaio de uma nova exposição da doutrina da ciência" soa da seguinte forma: "o eu põe-se pura e simplesmente como se pondo". ${ }^{12}$ Essa fórmula contém, conforme Henrich, uma explicação da produção do eu e da autoconsciência. O conceito do pôr representa, para Henrich, uma atividade ou ação no sentido de um processo de produção ${ }^{13}$ por meio do qual é produzido algo que não existe antes do pôr e que se encontra em relação com o saber. No caso do pôr-se pura e simplesmente, o pôr é o único fundamento da autoconsciência. Daí que: "o que se põe pura e simplesmente chega ao ser-para-si sem nenhum fundamento." ${ }^{14}$ A expressão 'ser-para-si' significa autoconsciência. Autoconsciência é um produto do pôr. O termo 'pura e simplesmente' significa, conforme Henrich, "que ele [isto é, o pôr] não se dá através de algo previamente já posto ou com referência a um tal." ${ }^{15}$ Pôr-se, portanto, é um processo de produção, que não tem lugar por meio de algo produzido por um outro pôr e que tampouco se encontra em um relação com algo já produzido por um outro pôr. $O$ eu não é produzido por uma atividade que não é atribuível ao eu. Ao contrário, o eu surge com o pôr. ${ }^{16}$

Segundo Henrich, Fichte desenvolve uma explicação da autoconsciência que vai muito além daquilo que fora dito até então. A atividade do pôr é (também) uma atividade do pensamento. ${ }^{17}$ Segundo Fichte, o pôr inclui em si uma intuição dessa atividade e com isso também uma intuição do eu - assim deve entender Henrich, presumivelmente. ${ }^{18}$ Mediante a intuição a existência do eu é reconhecida e assegurada. Para Fichte - 
segundo Henrich -,a intuição sozinha, contudo, não é suficiente para que a autoconsciência esteja presente. Sem um conceito, o sujeito não poderia entender que ele vê a si mesmo. ${ }^{19}$ Por isso, a autoconsciência inclui também um componente conceitual que determina o pôr. Isso não causa admiração, já que, afinal, o pôr (também) é uma atividade do pensamento. Na "fórmula" - "o eu põe-se pura e simplesmente como se pondo" - isso é expresso, segundo Henrich, pelo eu pôr a si mesmo como se pondo. Henrich interpreta a palavra 'como' (als) no sentido de uma representação conceitual. ${ }^{20}$ Por essa razão, a interpretação de Henrich de Fichte é designada no título desta seção como um modo "epistemológico" de leitura. Autoconsciência se baseia, assim, na unidade de intuição e conceito que se faz presente com a atividade do pôr: ${ }^{21} \mathrm{o}$ componente conceitual possibilita a obtenção da informação egológica de que se é mesmo o sujeito que põe ou é ativo. ${ }^{22} \mathrm{~A}$ intuição apreende e assegura a existência do eu.

Fichte não desenvolve, por conseguinte, somente uma explicação da produção do eu e da autoconsciência, mas também da constituição da autoconsciência. ${ }^{23}$ Os componentes necessários da autoconsciência que podem ser identificados em Fichte, segundo a leitura de Henrich, são a atividade do pôr e, com ela também, a atividade do pensamento, bem como a intuição e o conceito. Esses componentes estão em tal relação entre si que com o pôr há uma intuição dessa atividade, que assegura a existência da atividade e, com ela, do sujeito, assim como, em decorrência de um ato do pensamento que se dá com o pôr, existe uma determinação ou representação conceitual, com auxílio da qual fica disponível a informação consciente de ter consciência de si mesmo como o sujeito ou como eu. Nisto, intuição e conceito formam uma unidade. Em virtude dessa relação desses componentes entre si, existe a informação consciente de ser o próprio sujeito ponente (existente). ${ }^{24}$

No entanto, conforme Henrich, Fichte não logra explicar de maneira convincente, no "Ensaio de uma nova exposição da doutrina da ciência", a estrutura do eu e de sua autoconsciência. Henrich formula duas objeções. A primeira objeção afirma o seguinte: "a força de produção do eu ponente (...) tem de produzir em um instante o ter-a-si do eu conjuntamente com um saber de si. Não podemos tornar claro como ela consegue fazê-lo, pois todo saber já se encontra sob a duplicidade cujo esclarecimento está em questão. Mas o eu deve pôr-se 'como' si mesmo. Se ele é aquela força de produção, então ele teria de poder ver como se origina dele próprio a duplicidade de seu autoconhecimento." ${ }^{25}$ Henrich não esclarece mais essa objeção. É difícil determinar como ela deve ser entendida de modo preciso. Eu tendo à seguinte interpretação: (a) ao "ter-a-si do eu" mencionado na citação corresponde a intuição do eu e ao "saber de si", o componente conceitual. ${ }^{26}$ Por isso, a locução "duplicidade de seu autoconhecimento" tem o sentido de intuição do eu e saber conceitual do eu. (b) Henrich admite que, para Fichte, o eu é completamente transparente para ele mesmo. Isso significa que o eu reconhece todas as suas propriedades que estão em jogo com a enunciação do eu como pôr-se pura e simplesmente como ponente. Isso explica por que Henrich alega na citação que o eu tem de poder ver como se originam da força de produção intuição e conceito: já que, em virtude do pôr, intuição e conceito existem e o eu é completamente transparente para si, a consciência da atividade do sujeito também tem de apreender o modo como intuição e conceito "se originam", isto é, supostamente resultam da atividade. A explicação de Fichte da estrutura do eu e da autoconsciência não inclui, no entanto, nenhuma informação sobre o modo como a intuição e o conceito se originam do pôr-se. ${ }^{27}$ Por isso, também permanece inexplicado como o eu pode "ver" como 
intuição e conceito resultam da força de produção. Na explicação de Fichte da estrutura do eu e da autoconsciência não está dada a completa transparência do eu, embora ela teria de ser garantida.

A segunda objeção afirma o seguinte: "Seu produto [i.e. da produção, S.L.] é o saber enquanto unidade de uma intuição e de um conceito da atividade. Ora, se o saber está completamente determinado através destes dois momentos e se estes são produto de uma produção, - deve então também a produção ser o que é sabido no produto? Que assim seja, a fórmula do pôr-se do eu (...) o exige." ${ }^{28}$

Dois modos de leitura fazem sentido nesta segunda objeção. A pergunta formulada na citação pode ser interpretada como uma crítica a Fichte tanto do ponto de vista da teoria da consciência quanto também daquele da lógica da produção. Segundo o modo de ler da teoria da consciência, a objeção afirma que o saber ou a autoconsciência tem de conter em sua efetuação, como produto do pôr, a consciência da produção. Afinal de contas, "a fórmula do pôr-se do eu" exige isso. Mas isso é impossível. Se a autoconsciência é o produto da atividade, ela não pode conter nenhuma informação consciente sobre $o$ ato que se encontra em seu fundamento ou o antecede. 0 processo de produção se encontra, por assim dizer, "nas costas" da autoconsciência ou em seu "ponto cego". Daí que não é compreensível como o processo de produção pode ser um conteúdo consciente da autoconsciência. Segundo o modo de ler da lógica de produção, a objeção diz que a autoconsciência tem de conter uma informação consciente sobre o processo de produção que a produz, visto que o eu põe a si mesmo. Isso, contudo, só é possível se a produção é um componente de seu produto, isto é, da autoconsciência e, aliás, na figura daquilo que é sabido pela autoconsciência. ${ }^{29}$ Mas isso está excluído. 0 produto não pode conter sua produção.

Conforme esse modo de ler a objeção, Henrich retorna, segundo o conteúdo, a uma crítica a Fichte que ele, n' "O insight originário de Fichte", alegou contra o ponto de vista fichteano da "Fundação de toda a doutrina da ciência". Fichte, de acordo com Henrich, explica a estrutura do eu na "Fundação de toda a doutrina da ciência" com base na seguinte fórmula: "o eu põe-se pura e simplesmente". ${ }^{30}$ Conforme Henrich, essa fórmula deve ser entendida especialmente do seguinte modo: "que mesmo o sujeito só emerge simultaneamente com toda a consciência eu=eu. (...) Quando Fichte fala do pôr$s e$ do eu, ele tem em mente, então, essa imediatez na qual todo o eu emerge de uma só vez. (...) O eu é um pôr, é aquele agir, pelo qual surge seu ser-para-si, um eu-sujeito toma consciência de si como eu-objeto." ${ }^{11}$ Por conseguinte, é válido, para Henrich, que (a) a autoconsciência existe por meio da atividade do pôr, que (b) o eu consiste nesse pôr ou produzir, e que (c) não existe nenhum sujeito antes da autoconsciência. Ao contrário, o eu ou o sujeito emergem primeiramente com a autoconsciência. Com o conceito de "pôr-se" na "Fundação de toda a doutrina da ciência" Henrich vincula ainda, no entanto, mais um pensamento. $O$ pôr-se deve (d) indicar uma relação e - isto significa - incluir uma distinção da lógica de produção..$^{32}$ Atividade e saber ou produção e produto se distinguem. A atividade é meramente o fundamento do saber. Ela mesma, contudo, não é um saber. ${ }^{33}$ Decerto, a atividade não existe sem seu produto, a autoconsciência. Porém, ela não é, de fato, nenhum saber, mas sim é distinta da autoconsciência enquanto seu produto. 0 modo de ler da lógica de produção da crítica de Henrich ao ponto de vista de Fichte no "Ensaio de uma nova exposição da doutrina da ciência" retoma essa distinção da lógica de produção entre atividade e autoconsciência. Em face dessa diferença vale o fato de que o pôr não pode ser um 
elemento de seu produto, da autoconsciência e, com ela, daquilo que é sabido com base nela, já que produzir e produto devem ser obrigatoriamente distinguidos. Visto que, para Fichte, a autoconsciência deve conter uma consciência do pôr, a produção teria de ser, contudo, um componente do produto, da autoconsciência na forma daquilo que é sabido.

Qualquer que seja a forma como devem ser entendidas as objeções de Henrich, resulta delas, segundo seu modo de ver, um pensamento pleno de consequências: "Desse modo, forma-se um pensamento que faz preceder ao eu ativo um fundamento ativo, a partir do qual se explica a unidade co-originária de seus momentos, mas que nele não vem à presença. Não este último, mas somente o seu resultado pode ser denominado 'eu'." 34 Também se tornou questionável se "o eu, em última instância, está determinado por meio da enunciação do 'pôr a si mesmo", tal como Fichte o constata. ${ }^{35} \mathrm{O}$ ponto de vista de Fichte em suas primeiras doutrinas da ciência parece estar errado em seu fundamento.

\section{Uma interpretação ontológica alternativa}

Henrich desenvolve uma interpretação epistemológica do significado da palavra 'como' (als) na fórmula "o eu põe-se pura e simplesmente como se pondo". Essa palavra deve significar uma representação conceitual. Christian Klotz, no entanto, criticou a interpretação de Henrich e apresentou um modo de leitura alternativo da estrutura do eu e de sua autoconsciência. Klotz chama a atenção para o fato de que a palavra 'como' (als) não significa que há uma representação conceitual. Isso é válido ao menos quando Fichte tematiza a autoconsciência originária no "Ensaio de uma nova exposição da doutrina da ciência", a qual, segundo Klotz, é investigada por Henrich em sua análise do "Ensaio de uma nova exposição da doutrina da ciência". ${ }^{36}$ Para Klotz, a autoconsciência originária é um caso de autoconsciência não-conceitual. Se autoconsciência, em contrapartida, inclui em si um componente conceitual, trata-se de uma autoconsciência intencional: com o auxílio de um conceito o eu representa a atividade complexa do pôr e, com isso, o sujeito ou a si mesmo, de modo que há uma diferença entre o representante e o representado. 0 sujeito, que graças ao conceito tem consciência de si mesmo, se distingue do sujeito na medida em que é consciente. De um lado, o sujeito tem consciência de algo ou é, para falar com Fichte, "o sujeito consciente" ("das Bewusstseyende") que é consciente de um conteúdo conceitualmente determinado. De outro lado, o sujeito está conceitualmente determinado e é, com isso, o objeto de referência do conceito ou, para falar com Fichte, um objeto consciente (para o sujeito consciente (das Bewusstseiende)). ${ }^{37}$ De acordo com Klotz, Fichte não defende, porém, o ponto de vista de que a autoconsciência originária seja constituída intencionalmente. Isso é reconhecível, em particular, pelo fato de que Fichte no "Ensaio de uma nova exposição da doutrina da ciência" elucida a estrutura do eu e de sua autoconsciência originária em conexão com seu "argumento do regresso" ${ }^{38}$ Com o argumento do regresso Fichte quer dizer, entre outras coisas, que uma interpretação intencional da autoconsciência originária desemboca em um regresso infinito pernicioso. Não é possível esclarecer aqui o argumento do regresso. ${ }^{39}$ Decisivo é o seguinte ponto: visto que, com efeito, está fora de dúvida que, para Fichte, a autoconsciência originária existe, é necessária uma interpretação alternativa da estrutura desse caso de autoconsciência. Ela não pode ser constituída intencionalmente. Do contrário, Fichte 
refutaria sua própria posição com o argumento do regresso. Isso significa também que a palavra 'como' (als) não pode ser entendida no sentido de uma representação conceitual quando essa palavra é empregada na descrição da autoconsciência originária, já que, neste caso, a autoconsciência estaria constituída intencionalmente. Por conseguinte, Henrich comete o erro de interpretar a autoconsciência originária como um caso de autoconsciência intencional, ao passo que Fichte, justamente, não defende esse ponto de vista. Isso não significa que, segundo Klotz, tampouco haja para Fichte autoconsciência intencional. Ao contrário, Klotz também reconstrói a compreensão fichteana de autoconsciência intencional. Klotz, no entanto, mostra que, para Fichte, autoconsciência intencional pressupõe autoconsciência não-intencional..$^{40} \mathrm{Klotz}$ tem razão. $\mathrm{O}$ argumento do regresso mostra (do ponto de vista do conteúdo) que uma interpretação intencional da autoconsciência originária conduz a um regresso infinito pernicioso. Esse caso de autoconsciência não pode, portanto, ser constituído intencionalmente. Ao meu ver, trata-se, neste caso de autoconsciência, de consciência não-conceitual de ser ela mesma o sujeito epistêmico - portanto, de ser o sujeito que tem consciência - e de ser ela mesma o sujeito pensante. Isso é significativo para o julgamento da interpretação sobre Fichte de Henrich. $\mathrm{O}$ eu, incluída sua autoconsciência originária, é (ao meu ver) o princípio da doutrina da ciência. ${ }^{41} \mathrm{Em}$ sua análise da estrutura do eu, Henrich se concentra igualmente no princípio da doutrina da ciência. A análise de Henrich, por isso, não pode estar correta, já que a autoconsciência, ao seu ver, encerra um componente conceitual e é constituída, por conseguinte, intencionalmente. Uma comparação da caracterização de Henrich do princípio da doutrina da ciência com os termos do "Ensaio de uma nova exposição da doutrina da ciência" fortalece a dúvida na interpretação de Henrich. Fichte explica que o eu se caracteriza por consistir em um "pôr-se como pondo, (algo objetivo, que também pode ser eu mesmo, como mero objeto)." ${ }^{42}$ Esta é a caracterização literal de Fichte do princípio da doutrina da ciência no "Ensaio de uma nova exposição da doutrina da ciência". Segundo Henrich, contudo, o princípio soa algo diverso. Ele deve consistir em um pura e simplesmente "pôr-se como se pondo". Se comparamos as duas formulações, saltam à vista as seguintes diferenças: (1) para Henrich, o eu põe-se como se pondo, enquanto Fichte justamente não explica que o eu põe-se exclusivamente como se pondo, mas sim põe-se como pondo "algo objetivo". Esse objeto pode ser o eu, mas não tem de sê-lo. Também pode ser algo outro que o eu aquilo que é posto como objeto. Neste caso, não é válido que o eu põe-se como se pondo. (2) Por isso, tampouco surpreende o fato de que Henrich, em sua caracterização do princípio da doutrina da ciência, não toma em consideração a indicação de Fichte de que o eu não se põe meramente como pondo, mas põe simultaneamente com isso "algo objetivo". ${ }^{43} \mathrm{~A}$ menção de Fichte do pôr de um objeto, que pode ser o eu, mas não tem de sê-lo, não é tematizada por Henrich.

Essas indicações filológicas não são uma brincadeira sem sentido. Fichte refletiu muito bem sobre a escolha das palavras. Se atentamos às indicações de Klotz, fica evidente um modo de leitura alternativo do princípio da doutrina da ciência. ${ }^{44}$ Ele se caracteriza pelas seguintes teses:

(a) Fichte desenvolve uma interpretação ato-ontológica (aktontologische). 0 eu consiste na atividade que Fichte caracteriza com as palavras "pôr-se como pondo". ${ }^{45} \mathrm{O}$ eu não é, eventualmente, um produto do pôr que fosse diferente do pôr e, por consequência, produzido por algo outro. ${ }^{46} \mathrm{O}$ eu se põe espontaneamente, isto é, autoativamente, de modo que a gênese do eu não pode ser explicada por razões ou também causas 
externas. ${ }^{47}$ Os componentes do eu tampouco surgem sucessivamente, de tal modo que, primeiramente o eu se põe e a seguir põe a si mesmo como pondo. A complexa estrutura emerge de um golpe. Visto que o eu consiste justamente nessa estrutura, a fórmula "pôr-se como pondo" contém uma explicação ato-ontológica da constituição do eu. Os componentes necessários do eu são o pôr-se e o pôr como pondo. A "fórmula" de Fichte elucida a relação necessária entre esses componentes. $O$ eu não consiste no "pôrse" e no "pôr como pondo", mas ele consiste no pôr-se como pondo.

(b) A palavra "pôr" designa, entre outras coisas, uma atividade espontânea do pensamento, a qual, por consequência, aplica conceitos e com a qual está presente a consciência daquilo que é pensado. Os conceitos determinam o respectivo objeto consciente ${ }^{48} \mathrm{O}$ pôr e com ele também a atividade do pensamento inclui uma intuição da atividade espontânea do pensamento. Essa intuição não é sensível. Ela é uma intuição sui generis. A atividade do pensamento ou o pôr não incluem, porém - diferentemente da concepção de Henrich -, um conceito que determinaria a atividade do pensamento e o pôr. Conceitos determinam exclusivamente o que é pensado pelo ato do pensamento, o objeto ("algo objetivo"), mas não também a atividade e, com ela, o próprio sujeito pensante ${ }^{49} \mathrm{Na}$ explicação da consciência, de ela ser ela mesma o sujeito pensante e epistêmico, os conceitos não desempenham nenhum papel. ${ }^{50}$ Segundo Fichte, não é com o auxilio de um conceito que o eu conhece que ele tem consciência de si mesmo. $O$ sujeito possui essa informação egológica em virtude da intuição sui generis. Reconhece-se isso também pelo fato de Fichte não mencionar conceitos nas passagens nas quais ele elucida o princípio da sua doutrina da ciência, isto é, na seção II do "Ensaio de uma nova exposição da doutrina da ciência". Fichte tematiza conceitos e discute sua relação com a intuição apenas na seção III do "Ensaio de uma nova exposição da doutrina da ciência" e, com isso, em conexão com a introdução e elucidação da estrutura do eu no sentido do princípio da doutrina da ciência.$^{51}$ As explicações da seção III mostram que a autoconsciência conceitual só se realiza quando o sujeito assume o papel do objeto da consciência intencional.

É importante notar que Fichte emprega frequentemente a palavra 'consciência' no sentido de que a consciência inclui em si, junto com a intuição sui generis não-sensível, uma intuição sensível assim como componentes conceituais..$^{52} \mathrm{Se}$, no percurso feito até aqui desta investigação, a autoconsciência não-intencional foi de tal maneira caracterizada que ela consiste na informação consciente de ser ela mesma o sujeito pensante e epistêmico, então, não é visado com a expressão 'informação consciente' essa significação frequentemente empregada por Fichte da palavra 'consciência'. A autoconsciência não-intencional do sujeito pensante e epistêmico não encerra em si nem um conceito do sujeito e de sua atividade nem uma intuição sensível. A fim de evitar confusões terminológicas, serão evitadas na sequência para o caso da auto "consciência" não-intencional, formulações como 'informação consciente de ser ela mesma o sujeito pensante e epistêmico' e outras semelhantes, até onde isso for linguisticamente propício. Em vez disso, serão empregadas as palavras 'certeza' ou mesmo 'intuição'.

Dessa maneira, Fichte desenvolve não apenas uma explicação ato-ontológica da constituição do eu, mas, além disso, uma explicação epistêmica da constituição da certeza de ser o sujeito pensante e epistêmico da consciência. Os componentes constitutivos são o sujeito, a atividade do pensamento e a intuição sui generis presente com o pôr. A relação entre esses componentes consiste em que o sujeito, em virtude do 
seu pensamento, tem consciência - de um objeto - e, com o auxílio da intuição, reconhece a atividade do pensamento e o sujeito que tem consciência (o sujeito consciente ("das Bewusstseyende"), de modo que se faz presente a certeza de ser ele mesmo o sujeito pensante e epistêmico da consciência. ${ }^{53}$ Mas a autoconsciência nãointencional não inclui em si a representação de ser o objeto consciente. A explicação da constituição da consciência de um objeto intencional determinado conceitualmente contém, ante a explicação da autoconsciência originária, componentes adicionais que, neste ponto, não precisam ser tematizados. ${ }^{54}$

(c) A atividade espontânea do pôr e, com ele, também do pensamento é, ela mesma, a intuição de si mesma. A atividade não produz a intuição no sentido de um produto que é distinto da atividade. A atividade é, antes, um fenômeno epistêmico-espontâneo que reconhece ou intui a si mesmo. Por essa razão, Fichte caracteriza o "pôr-se como pondo" com a "expressão científica" como intuição.$^{55} \mathrm{~A}$ intuição, portanto, não é nada mais que a complexa atividade de pôr. De acordo com isso, Fichte define na "Nova elaboração da doutrina da ciência" (1800): "O pensamento é, pois, consciência, - é consciência de si mesmo. - retorna a si mesmo." ${ }^{56} \mathrm{O}$ próprio pensamento é certeza de si mesmo. ${ }^{57}$ Portanto, a atividade do pôr inclui a atividade do pensamento $e$ a intuição da mesma. Isso significa também que a atividade do pôr e sua autoconsciência são cooriginários. O eu consiste na complexa estrutura do pôr, a qual apresenta simultaneamente, em virtude da intuição, a autoconsciência egológica. Por isso, Fichte recusa de modo resoluto a tese de que haveria um sujeito que existisse independentemente da sua autoconsciência ou mesmo que consistisse em algo outro que sua atividade espontânea e sua autoconsciência. ${ }^{58}$ Se o sujeito está presente como sujeito epistêmico e ativo, então sua existência inclui uma certeza egológica a respeito do sujeito epistêmico e ativamente pensante da consciência e, aliás, a certeza de ser ele mesmo o sujeito epistêmico e pensante da consciência.

(d) A expressão "a intuição (...) é um pôr-se como ponto" significa, portanto, (i) que o eu surge espontaneamente e consiste em sua atividade. Isso é expresso pela locução "é um pôr-se". Mas a expressão também significa - e isso é o principal ponto do modo de leitura ontológico alternativo -, (ii) que não permanece indeterminado quais propriedades o eu apresenta quando ele existe. A expressão 'pôr-se como pondo' indica, antes, como o eu existe quando ou tão logo ele existe. Trata-se aqui, portanto, de uma informação ontológica. ${ }^{59}$ Por isso, a palavra "como" ( als) não designa uma representação conceitual. A informação ontológica afirma, ao contrário, que quando se efetua a atividade espontânea do pensamento, na qual (também) consiste o eu, o eu existe como o sujeito epistêmico e ativo, isto é, pensante da consciência. ${ }^{60}$ Isso significa que, quando o eu existe, ele é, de um lado, o sujeito (epistêmico) da consciência, para o qual estão presentes conteúdos conscientes ou, nas palavras de Fichte, "algo objetivo". ${ }^{61}$ Ele é, além disso, um sujeito ativo e, aliás, ativo no sentido do pensamento e não um sujeito passivo ou receptivo.

(e) Há uma isomorfia entre os componentes constitutivos ato-ontológicos do eu, de um lado, e os componentes "teórico-conscientes" da autoconsciência, de outro: à locução "pôr-se" corresponde a certeza de ser o próprio sujeito. À locução "como pondo" corresponde a certeza de ser o próprio sujeito pensante e, assim, de ser também o sujeito epistêmico que tem consciência (de algo). Por conseguinte, a descrição atoontológica de Fichte da constituição do eu concorda com sua caracterização "teóricoconsciente" da autoconsciência. Essa concordância também é exigida ou ao menos 
desejada, já que a atividade espontânea do pôr deve ser ela própria a intuição ou a autoconsciência (cf. ponto c). A constituição do eu e certos conteúdos da intuição devem, por isso, ser figuráveis ou traduzíveis reciprocamente 1 por 1 .

Com essas reflexões estão nomeados os pontos centrais do princípio da doutrina da ciência. E no entanto, no percurso feito até aqui não foi levada mais detidamente em consideração a expressão entre parênteses da fórmula, ou seja, a locução "(algo objetivo, que também pode ser eu mesmo, como mero objeto)". E isso, por boas razões. Fichte pôs os parênteses a fim de sinalizar que a expressão entre parênteses não tematiza mais o princípio da doutrina da ciência. ${ }^{62} \mathrm{O}$ princípio consiste na certeza de ser o próprio sujeito pensante e epistêmico da consciência e na estrutura ato-ontológica do eu correspondente a essa certeza. Por isso, é importante atentar para o fato de que neste ponto da investigação está em um primeiro momento concluído o modo de leitura ontológico da estrutura do eu no sentido do princípio da doutrina da ciência. ${ }^{63}$

A despeito disso, é instrutivo com vistas à interpretação de Fichte feita por Henrich considerar conjuntamente o significado da observação entre parênteses. Pois o sujeito não se realiza apenas como sujeito pensante e epistêmico. Ele põe, ademais, "algo objetivo". Isso significa que o sujeito produz a estrutura da consciência intencional. Essa admissão é evidente. Afinal de contas, o pôr também é uma atividade do pensamento, de modo que com o pôr é produzida uma relação intencional. Com o pensamento é aplicado um conceito que determina o objeto da consciência. A expressão "algo objetivo" representa esse correlato objetivo, isto é, conceitualmente determinado da consciência intencional. No caso em que o conceito "eu" é aplicado, o eu é o objeto intencional, de maneira que há autoconsciência intencional. ${ }^{64}$ Essa possibilidade de que esteja presente a autoconsciência intencional é admitida pelo próprio Fichte ao detalhar que é posto algo objetivo "que também pode ser eu mesmo, como mero objeto".

Por isso, Fichte contempla também o ponto de vista de Henrich. Está plenamente previsto por Fichte, no âmbito de sua doutrina da ciência, que o eu se põe como se pondo. Este é, então, o caso quando está presente a autoconsciência intencional e o sujeito, por conseguinte, está consciente como objeto conceitualmente determinado. A explicação da autoconsciência intencional é um tema central da doutrina da ciência. Fichte mostra na "Doutrina da ciência nova methodo" que a autoconsciência intencional deve ser discutida sobretudo no contexto prático. ${ }^{65}$ Esse tema não pode ser elucidado mais pormenorizadamente neste ensaio. Mais importante, tendo em vista a crítica à interpretação de Fichte feita por Henrich, é o fato de que, para Fichte, a autoconsciência intencional pressupõe o princípio da doutrina da ciência e com ele a certeza (não intencional) de ser o próprio sujeito pensante e epistêmico da consciência.

\section{Objeções de Henrich e interpretação performativa}

Mesmo se devesse estar correto o modo de leitura alternativo da estrutura do eu e da autoconsciência para Fichte, exposto na segunda seção, ainda não está respondida a pergunta se convencem ou não as objeções de Henrich contra Fichte, reconstruídas na primeira seção. Por isso, é preciso examinar se as objeções de Henrich podem ser refutadas partindo do ponto de vista do modo de leitura ontológico de Fichte. A primeira objeção afirma que, no âmbito da teoria de Fichte, o eu teria de poder discernir como intuição e conceito surgem em virtude do pôr. No entanto, não é 
concebível como o eu pode "ver" como intuição e conceito se "originam" da força de produção. Essa objeção, pois, não convence mais. A autoconsciência não-intencional não inclui nenhum conceito. A certeza egológica de ter consciência de si mesmo não é obtida por meio de um conceito, mas da intuição sui generis. Em relação à autoconsciência, portanto, não é nem exigido nem possível "ver" o produzir do conceito. ${ }^{66}$ Ademais, o complexo pôr-se do eu não deve ser distinguido da intuição. $O$ ato é a intuição de si mesmo. Por essa razão, não é de modo algum possível o que Henrich exige, ou seja, de que o eu tem de "poder ver" "como dele [isto é da força de produção, S.L.] se origina a duplicação de seu autoconhecimento". ${ }^{67} \mathrm{~A}$ intuição não se origina da atividade espontânea. Não é possível uma explicação aprofundada da intuição a não ser que ela é um elemento do pôr e o reconhece.

Por ocasião da investigação da segunda objeção de Henrich, foram expostos dois modos de leitura de como essa objeção pode ser entendida. Segundo o modo de leitura da teoria da consciência, a segunda objeção afirma que a autoconsciência tem de conter uma informação consciente sobre o pôr ou sobre o processo de produção. Isso, contudo, não é possível, já que a autoconsciência é produto do processo de produção e esse processo se encontra, pois, em "suas costas". Essa objeção também não convence. Para Fichte, a atividade já inclui sempre uma intuição de si mesma e, com ela, a certeza de ser o sujeito ativo da consciência. Caso contrário, ela não se realiza. Caso contrário, ela, por assim dizer, não sai para fora da "caixa" (Starbox). Atividade e intuição e autoconsciência não devem, como Henrich pressupõe, ser distinguidas de tal modo que a atividade precederia a autoconsciência ou se encontraria em seu "ponto cego". Fichte menciona este ponto no "Ensaio de uma nova exposição da doutrina da ciência", quando explica, apoiando-se no argumento do regresso, que a consciência (nãointencional) do pensamento não deve ser separada desse mesmo pensamento: "a consciência do meu pensar não é eventualmente algo contingente ao meu pensar, só acrescentada a ele posteriormente e vinculada com ele, mas é inseparável dele." ${ }^{68} \mathrm{~A}$ objeção de Henrich repousa sobre um uma interpretação equivocada da relação entre a intuição e a atividade do pôr. A intuição é um elemento do pôr e compreende essa atividade em sua efetuação, por assim dizer, desde o início.

Segundo o modo de leitura da lógica de produção, a segunda objeção afirma que, para Fichte, a autoconsciência deve conter uma informação consciente sobre o pôr. Este é o caso quando o pôr é um elemento de seu produto, portanto, da autoconsciência. No entanto, isso não é possível, visto que está presente uma diferença da lógica de produção entre o pôr e a autoconsciência. A réplica a essa objeção não se distingue essencialmente da réplica à objeção anterior. Atividade e intuição não se distinguem do ponto de vista da lógica de produção, de modo que a intuição fosse o produto de uma atividade ou produção a ser distinguida dela. Ao contrário, a atividade sempre inclui a intuição dessa mesma atividade, logo, de si mesma. A intuição da atividade subsiste com a efetuação da atividade do pôr. Por isso, a atividade é certamente um elemento da autoconsciência na figura do conteúdo consciente. Tampouco essa objeção, portanto, convence conforme a diretriz do modo de leitura alternativo.

Ao mesmo tempo, essa réplica às objeções de Henrich se choca com uma resistência ou incompreensão. Essa réplica é em geral inteligível? É compreensível o enunciado de que a intuição é um elemento da atividade? A interpretação ontológica desenvolvida na segunda seção dessa investigação deveria poder responder a essas perguntas. Do contrário, a réplica apresentada às objeções de Henrich é pouco convincente. $O$ ponto 
de vista que eu defendo já há muito afirma que o princípio da doutrina da ciência é determinado conceitualmente, de forma adequada ao fenômeno, como um fenômeno performativo. Como isso deve ser entendido considerando-o mais detidamente?

Como se sabe, John Langshaw Austin introduziu na filosofia a expressão 'performativo'. Faz sentido, assim, orientar-se em Austin, ao menos de início, quando se trata da performatividade. Para a interpretação da relação entre a intuição ou a autoconsciência e a atividade espontânea do pôr, se oferecem, em particular, declarações performativas condutoras (konduktive performative Äußerungen), como, por exemplo: "eu te amaldiçoo!", "eu te parabenizo!" ou também "eu te peço desculpas!". ${ }^{69}$ Esse tipo de declarações revela propriedades notáveis. (a) Com uma declaração efetua-se uma ação, um ato ilocucionário: uma pessoa amaldiçoa alguém; uma pessoa parabeniza alguém; uma pessoa pede desculpas a alguém. (b) A significação linguística da declaração contém uma informação sobre a ação que é efetuada: o amaldiçoar, o parabenizar e o desculpar. (c) A significação linguística é, ademais, um elemento essencial da própria ação. ${ }^{70}$ Decerto, podem haver outros caminhos para, por exemplo, amaldiçoar alguém ou algo do que dizer: "eu te amaldiçoo!". É possível assim, por exemplo, que uma pessoa amaldiçoe outra pessoa com a declaração "suas vacas devem dar leite azedo pelos próximos 100 anos!". Essa declaração não contém um verbo "performativo" que tematiza a ação de amaldiçoar. Mas na declaração "eu te amaldiçoo", a significação linguística é um elemento essencial da ação de amaldiçoar. A ação de fala de amaldiçoar sucede através e com a declaração da expressão "eu te amaldiçoo!". A significação linguística é o meio por meio do qual a ação é efetuada. Reconhece-se isso, entre outras coisas, no fato de que amaldiçoar, ao menos no entendimento bíblico, consiste em uma pessoa pronunciar (determinadas) palavras, no caso presente, portanto, declarar "eu te amaldiçoo!". ${ }^{11}$

A ideia central da interpretação performativa do eu e da autoconsciência diz que a relação entre a intuição e a atividade pode ser compreendida em analogia com essa propriedade das declarações performativas apresentadas. Nos Prolegômenos, Immanuel Kant entende por uma analogia não uma "semelhança perfeita de duas coisas, mas uma semelhança perfeita de duas relações entre coisas inteiramente dessemelhantes". ${ }^{72} \mathrm{Eu}$ não afirmo que deve ser encontrada uma semelhança perfeita a respeito das propriedades das declarações performativas, de um lado, e das propriedades do pôr-se do eu e de sua intuição, de outro. São tomadas em consideração exclusivamente a dimensão da ação, a significação linguística das declarações performativas e sua relação entre si. Portanto, a analogia se limita aos três pontos indicados anteriormente que concernem à ação, à significação linguística e à sua relação entre si. Os demais aspectos das declarações performativas mencionadas - como, por exemplo, suas condições gerais para que as ações possam ser realizadas com sucesso ou mesmo o discurso de um si, um "eu", que, no caso da declaração "eu te amaldiçoo!", amaldiçoa alguém, o referente do pronome pessoal da segunda pessoa singular no acusativo -, não são tomados em consideração. Considerando essas limitações, no entanto, existem concordâncias suficientemente significativas entre essas duas relações para poder falar, com bastante razão, de uma explicação concebivel da relação entre a intuição e o pôr com a ajuda de uma analogia parcial. Na analogia, corresponde à intuição ou à autoconsciência a significação linguística das declarações performativas, e à atividade espontânea do pôr corresponde a ação que é efetuada com a declaração performativa. Daí que: tal como, por exemplo, no caso da declaração performativa "eu te amaldiçoo!" é efetuada uma ação, o amaldiçoar, que é tematizada pela significação linguística do 
verbo performativo, encontram-se com o pôr, em Fichte, tanto uma atividade quanto uma intuição dessa atividade. E tal como na declaração performativa a significação linguística é um elemento essencial da própria ação, do mesmo modo, a intuição da atividade espontânea é um elemento essencial da atividade do pôr mesmo. Por isso, não há uma diferença da lógica de produção entre a atividade e sua intuição. Graças às declarações performativas e a uma analogia, por conseguinte, é concebível como se pode tornar inteligível ou representar que uma atividade remete a uma intuição de si mesma: o pôr é um fenômeno egológico-performativo. Em decorrência da espontaneidade absoluta do pôr e do caráter performativo do pôr e da sua intuição, não é possível uma explicação completa da relação entre a intuição e a atividade. Isso significa que Fichte solucionou satisfatoriamente o enigma da autoconsciência e do eu? Mesmo se tornou-se possível, com a ajuda do modo de leitura performativo-ontológico, repelir as objeções de Henrich contra Fichte como não convincentes, isso não significa que, por isso, a teoria de Fichte é verdadeira. Eu tenho minhas dúvidas. Essas dúvidas não podem e não precisam ser expostas. O objetivo deste ensaio esgota-se na reconstrução da interpretação de Henrich da concepção fichteana da estrutura do eu e da autoconsciência e na investigação crítica de suas objeções com o auxílio de um modo de leitura alternativo do princípio da doutrina da ciência.

\section{Observação final}

A interpretação do ponto de vista de Fichte no "Ensaio de uma nova exposição da doutrina da ciência", desenvolvida neste artigo, surgiu a partir da já antiga confrontação com as investigações percursoras de Henrich. Como em muitos casos na lida com teorias clássicas, não poderemos saber ao fim e ao caso ou decidir definitivamente qual intepretação corresponde de fato à visão de Fichte. Não obstante, é importante formular objeções contra interpretações significativas. Uma filosofia viva e interessante se revela também por discutir abertamente interpretações sistematicamente relevantes e fundar propostas alternativas. Do ponto de vista sistemático, é vantajoso se são desenvolvidas diferentes interpretações que contêm reflexões interessantes e premissas inteligíveis. Fala em favor do modo de leitura aqui exposto o fato de que ele concorda com o teor da descrição fichteana do princípio da doutrina da ciência no "Ensaio de uma nova exposição da doutrina da ciência" e permite repelir as perspicazes objeções de Henrich contra Fichte.

\section{Bibliografia}

AUSTIN, John Langshaw. (2002): Zur Theorie der Sprechakte. Stuttgart.

BACH, Kent; HARNISH, Robert Mike. (1992): How Performatives Really Work. A Reply to Searle, in: Linguistics and Philosophy 15.

FICHTE, Johann Gottlieb (1965): Grundlage der gesammten Wissenschaftslehre (1794/95), in: Jacob, Hans; Lauth, Reinhard (Hgg.): Johann Gottlieb Fichte-Gesamtausgabe der Bayerischen Akademie der Wissenschaften. Bd. I.2. Stuttgart/Bad Cannstatt.

FICHTE, Johann Gottlieb (1970): Versuch einer neuen Darstellung der Wissenschaftslehre, in: Lauth, Reinhard/Gliwitzky, Hans (Hgg.): Johann Gottlieb Fichte-Gesamtausgabe der Bayerischen Akademie der Wissenschaften. Bd. I.4. Stuttgart/Bad Cannstatt. 
FICHTE, Johann Gottlieb (1970 a): Erste Einleitung in die Wissenschaftslehre, in: Gliwitzky, Hans/Lauth, Reinhard (Hgg.): Johann Gottlieb Fichte-Gesamtausgabe der Bayerischen Akademie der Wissenschaften. Bd. I.4. Stuttgart/Bad Cannstatt.

FICHTE, Johann Gottlieb (1970 b): Zweite Einleitung in die Wissenschaftslehre, in: Gliwitzky, Hans/Lauth, Reinhard (Hgg.): Johann Gottlieb Fichte-Gesamtausgabe der Bayerischen Akademie der Wissenschaften. Bd. I.4. Stuttgart/Bad Cannstatt.

FICHTE, Johann Gottlieb (1978): Wissenschaftslehre nova methodo WS 1796/99, in: Lauth, Reinhard (Hg.): Johann Gottlieb Fichte-Gesamtausgabe der Bayerischen Akademie der Wissenschaften. Bd. IV.2. Stuttgart/Bad Cannstatt.

FICHTE, Johann Gottlieb (1979): Neue Bearbeitung der Wissenschaftslehre, in: Lauth, Reinhard/ Gliwitzky, Hans (Hgg.): Johann Gottlieb Fichte-Gesamtausgabe der Bayerischen Akademie der Wissenschaften. Bd. II.5. Stuttgart/Bad Cannstatt.

HENRICH, Dieter (1966): Fichtes ursprüngliche Einsicht, in: Henrich, Dieter (Hg.): Subjektivität und Metaphysik. Festschrift für Wolfgang Cramer. Frankfurt am Main.

KANT, Immanuel (1995): Prolegomena zu einer jeden künftigen Metaphysik, die als Wissenschaft wird auftreten können. Textkritisch herausgegeben und mit Beilagen versehen von Rudolf Malter. Stuttgart.

KLOTZ, Christian (2002): Selbstbewusstsein und praktische Identität. Eine Untersuchung über Fichtes Wissenschaftslehre nova methodo. Frankfurt a.M.

LANG, Stefan (2021): Fichtes Regressargument und die Theorie des Selbstbewusstseins. Kritische Überlegungen zu Tobias Rosefeldts Interpretation, in: Freiburger Zeitschrift für Philosophie und Theologie.

ROSENTHAL, David M. (1997): A Theory of Consciousness, in: Block, Ned/Flanagan, Owen/ Güzeldere, Güven (Hgg.): The Nature of Consciousness: Philosophical Debates. Massachusetts.

STOLZENBERG, Jürgen (1986): Fichtes Begriff der intellektuellen Anschauung. Die Entwicklung in den Wissenschaftslehren von 1793/94 bis 1801/02. Stuttgart.

WERLITZ, Jürgen (Hg.) (2018): Die Bibel. Einheitsübersetzung. Kommentierte Studienausgabe. Lexikon und Begriffsregister. Mit Sacherklärungen, Themenschlüssel, Zeittafel, Karten. Band 4. Stuttgart.

\section{NOTAS}

1. HENRICH, Dieter (1966): Fichtes ursprüngliche Einsicht, in: Henrich, Dieter (Hg.): Subjektivität und Metaphysik. Festschrift für Wolfgang Cramer. Frankfurt am Main.

2. HENRICH 1966, p. 191; p. 193.

3. Henrich não menciona a distinção entre uma explicação da constituição e da produção do eu. Mas, do ponto de vista do conteúdo, tanto Henrich quanto Fichte desenvolveram teorias da constituição e da produção.

4. Uma explicação da produção do eu, portanto, não consiste necessariamente ou exclusivamente em uma explicação causal e materialista. Fichte, por exemplo, exclui a 
possibilidade de uma tal explicação. FICHTE, Johann Gottlieb (1970 a): Erste Einleitung in die Wissenschaftslehre, in: Gliwitzky, Hans/Lauth, Reinhard (Hgg.): Johann Gottlieb FichteGesamtausgabe der Bayerischen Akademie der Wissenschaften. Bd. I.4, Stuttgart/Bad Cannstatt. p. 196-197.

5. Cf., por exemplo, ROSENTHAL, David M. (1997): A Theory of Consciousness, in: Bock, Ned/Flanagan, Owen/Güzeldere, Güven (Hgg.): The Nature of Consciousness: Philosophical Debates. Massachusetts. Nesse exemplo, os componentes necessários são os dois estados mentais, e sua relação necessária consiste no fato de um desses dois estados mentais, qual seja, o pensamento, representar o outro atualmente de uma maneira nãoinferencial. Tão logo falta uma desses componentes ou também não existe essa relação, não subsiste a consciência do estado.

6. As palavras 'eu' e 'sujeito' são empregas como equivalentes no que segue.

7. Em sua análise da estrutura do eu n' "O insight originário de Fichte”, Henrich emprega as palavras 'saber' e 'autoconsciência' (tanto quanto eu o vejo) sinonimamente.

8. Isso vale, certamente, para a "Fundação de toda a doutrina da ciência", o "Ensaio de uma nova exposição da doutrina da ciência", a "Doutrina da ciência nova methodo" e também a "Nova elaboração da doutrina da ciência (1800)". FICHTE, Johann Gottlieb (1965): Grundlage der gesammten Wissenschaftslehre (1794/95), in: Jacob, Hans/Lauth, Reinhard (Hgg.): Johann Gottlieb Fichte-Gesamtausgabe der Bayerischen Akademie der Wissenschaften. Bd. I.2. Stuttgart/Bad Cannstatt. FICHTE, Johann Gottlieb (1970): Versuch einer neuen Darstellung der Wissenschaftslehre, in: Lauth, Reinhard/Gliwitzky, Hans (Hgg.): Johann Gottlieb Fichte-Gesamtausgabe der Bayerischen Akademie der Wissenschaften. Bd. I.4. Stuttgart/Bad Cannstatt. FICHTE, Johann Gottlieb (1978): Wissenschaftslehre nova methodo WS 1796/99, in: Lauth, Reinhard (Hg.): Johann Gottlieb Fichte-Gesamtausgabe der Bayerischen Akademie der Wissenschaften. Bd. IV.2. Stuttgart/Bad Cannstatt. FICHTE, Johann Gottlieb (1979): Neue Bearbeitung der Wissenschaftslehre, in: Lauth, Reinhard/ Gliwitzky, Hans (Hgg.): Johann Gottlieb Fichte-Gesamtausgabe der Bayerischen Akademie der Wissenschaften. Bd. II.5. Stuttgart/Bad Cannstatt.

9. HENRICH 1966, p. 195; p. 231; p. 288.

10. 0 "Ensaio de uma nova exposição da doutrina da ciência" deveria ter sido a exposição publicada da "Doutrina da ciência nova methodo". No entanto, Fichte publicou dessa doutrina da ciência apenas algumas reflexões sob o título "Ensaio de uma nova exposição da doutrina da ciência", adicionando a elas duas introduções.

11. KLOTZ, Christian (2002): Selbstbewusstsein und praktische Identität. Eine Untersuchung über Fichtes Wissenschaftslehre nova methodo. Frankfurt a.M.

12. HENRICH 1966, p. 202; p. 204.

13. No que segue, as palavras "atividade", "ação" e "ato" são empregadas sinonimamente.

14. HENRICH 1966, p. 200.

15. HENRICH 1966, p. 199.

16. Henrich menciona isso em sua exposição da posição de Fichte na "Fundação de toda a doutrina da ciência", isto é, algumas páginas antes de Henrich investigar o "Ensaio de uma nova exposição da doutrina da ciência". HENRICH, 1966, p. 199. Henrich não menciona isso em seu tratamento do "Ensaio de uma nova exposição da doutrina da ciência". Eu parto da ideia, contudo, de que, conforme Henrich, isso também vale para o ponto de vista de Fichte no "Ensaio de uma nova exposição da doutrina da ciência". 
17. Em sua interpretação do "Ensaio de uma nova exposição da doutrina da ciência", Henrich não utiliza a palavra "pensamento". No entanto, o pôr, para Henrich, inclui em si presumivelmente o pensamento, já que, conforme ele, entram em cena, em conexão com o pôr, um conceito e um pensamento. HENRICH, 1966, p. 203-204. Isso será melhor esclarecido na sequência.

18. Para Henrich, a consciência da atividade do pôr parece apresentar ao mesmo tempo a consciência do eu. Cf. HENRICH, 1966, p. 200-201. Isso pode ser explicado pelo fato de o eu consistir no pôr, isto é, em uma atividade. Tão logo exista consciência dessa atividade, há ao mesmo tempo também consciência do eu.

19. HENRICH, 1966, p. 204. Por outro lado, o componente conceitual também depende, segundo Henrich, da intuição. Conceitos, considerados sozinhos por si, não garantem a existência daquilo que eles representam. Como mencionado, a intuição apreende e assegura a existência do eu. Conforme Henrich, o eu existe sempre quando autoconsciência (egológica) está presente.

20. HENRICH 1966, p. 202-204.

21. HENRICH 1966, p. 205.

22. HENRICH 1966, p. 204.

23. Como mencionado, Henrich não elucida a diferença entre constituição e produção. A designação da análise de Henrich como de uma explicação teórica da constituição da autoconsciência é uma interpretação de sua investigação.

24. É discutível qual informação consciente a autoconsciência contém para Fichte, segundo Henrich. Henrich menciona que ela contém a informação consciente de ser ponente e de ter de si mesma consciência, assim como ela encerra em si uma certeza de existência em virtude da intuição. HENRICH, 1966, p. 204. É questionável se ela contém outras informações conscientes, como a informação de ser o sujeito da consciência de objetos e da experiência que ela faz. Em sua interpretação do "Ensaio de uma nova exposição da doutrina da ciência" Henrich não menciona isso explicitamente. Não obstante, Henrich menciona em sua discussão do assim chamado modelo da reflexão da autoconsciência, no seu "O insight originário de Fichte" -, portanto, algumas páginas antes de sua investigação acerca do "Ensaio de uma nova exposição da doutrina da ciência" de Fichte - , que no caso da autoconsciência está presente "saber de si enquanto subjetividade que sabe" HENRICH, 1966, p. 196. Por consequência, autoconsciência (para Fichte), segundo Henrich, também poderia conter a informação consciente de ser ela mesma o sujeito do saber.

25. HENRICH, 1966, p. 205.

26. Em favor dessa interpretação falam as seguintes passagens n' "O insight originário de Fichte": "A imediatidade de seu ter-a-si sugere tomá-lo por um modo de intuição." HENRICH, 1966, p. 192. O “ter-a-si”, mencionado na citação inserida no corpo do texto, é vinculado nesta citação com a intuição. "Afinal, ela inclui o fato de que o eu possui um saber daquilo que ele é. (...). Portanto, é preciso admitir, desse modo, que pertence ao eu (...) um momento de caráter conceitual.” HENRICH, 1966, p. 204. Nesta passagem, o saber é colocado em relação com o componente conceitual.

27. Por isso, vige a afirmação de que não se pode tornar claro para si o modo como a força de produção pode produzir "em um instante o ter-a-si do eu conjuntamente com um saber de si".

28. HENRICH, 1966, p. 205-206. 
29. Esse modo de leitura da objeção interpreta a palavra "ser" no trecho da citação "deve então também a produção ser o que é sabido no produto" de tal maneira que, como Henrich a entende, a própria produção é o que sabido.

30. HENRICH 1966, p. 198. Cf. FICHTE 1965, p. 261: "o eu põe originariamente e pura e simplesmente seu próprio ser".

31. HENRICH, 1966, p. 199.

32. HENRICH, 1966, p. 200.

33. HENRICH, 1966, p. 200: "No entanto, evidentemente, ela [atividade, S.L.] tem de ser distinguida do seu produto. E só esse produto é doravante saber, ao passo que a atividade só há de ser pensada como fundamento do saber se esse fundamento também é apreendido no saber e se a atividade é posta 'para-si'."

34. HENRICH, 1966, p. 206.

35. HENRICH, 1966, p. 205.

36. KLOTZ, 2002, p. 95-96. Não será discutida aqui pormenorizadamente a compreensão de Klotz da estrutura do eu a da autoconsciência.

37. Esta é a minha caracterização da autoconsciência intencional. Cf. KLOTZ 2002, p. 16.

38. FICHTE 1970, p. 274-275. KLOTZ 2002, p. 96.

39. KLOTZ 2002, p. 86-97. LANG, Stefan (2021): Fichtes Regressargument und die Theorie des Selbstbewusstseins. Kritische Überlegungen zu Tobias Rosefeldts Interpretation, in: Freiburger Zeitschrift für Philosophie und Theologie..

40. KLOTZ 2002, p. 16; p. 95-96.

41. Klotz parece não compartilhar deste ponto de vista. Cf. KLOTZ 2002, p. 16.

42. FICHTE, 1970, p. 276. (p. 182 da tradução brasileira: FICHTE, J. G. (1984) “O princípio da doutrina-da-ciência". Os Pensadores. Trad. Rubens Rodrigues Torres Filho. São Paulo: Abril Cultural. - N.do T.).

43. Henrich cita a passagem na qual Fichte caracteriza o princípio da doutrina da ciência da seguinte maneira: "A intuição da qual se trata aqui é um pôr-se como pondo (...), de modo algum, porém, um mero pôr". HENRICH, 1966, p. 203. Depois dos três pontos, porém, Fichte indica "(algo objetivo, que também pode ser eu mesmo, como mero objeto)". É significativo que Henrich não cite essa parte da frase.

44. 0 modo de leitura de Fichte exposto na sequência não pretende concordar com as perspectivas de Klotz, mesmo se, em todo caso, ela seja influenciada por Klotz. Ademais, vale lembrar que mesmo quando é desenvolvido um modo de leitura alternativo da estrutura do eu, subsistem certamente concordâncias pontuais com a interpretação de Henrich. Essas concordâncias não serão mencionadas em particular.

45. A doutrina da ciência mostra quais propriedades o eu apresenta adicionalmente. Dentre essas propriedades contam-se, por exemplo, atividades como o esforço e o impulso.

46. Na medida em que por uma produção entende-se exclusivamente uma atividade ou mesmo um processo que produz um produto a ser distinguido da atividade, Fichte não desenvolve nenhuma explicação da produção do eu. Segundo Fichte, porém, o eu não é um dado, mas ele surge (entsteht) e, aliás, em virtude de sua própria atividade. Em vez de se atribuir a Fichte uma teoria da produção, seja válido talvez falar de uma teoria da gênese (Entstehen). No \$1 da "Fundação de toda a doutrina da ciência", no entanto, Fichte emprega a palavra 'produção'. Nessa medida, é adequado ao conteúdo falar, em relação à explicação de Fichte da gênese do eu, de uma explicação da produção do eu. Para Fichte, não é todo caso de uma produção um processo no qual há uma diferença 
entre a produção e o produto. A expressão 'Tathandlung' responde por uma tal forma alternativa de produção. FICHTE 1965, p. 259.

47. 0 eu existe apenas, no entanto, quando há um conteúdo ou um "travo" (Anstoß), que não é produzido pelo eu e com o qual ele está em relação. FICHTE 1965, p. 369; p. 386-387; p. 405.

48. Na "fórmula", corresponde ao objeto consciente a expressão "algo objetivo".

49. Como mencionado, isso vale para o eu e sua autoconsciência no sentido do princípio da doutrina da ciência.

50. Isso vale para o "Ensaio de uma nova exposição da doutrina da ciência". Na "Doutrina da ciência nova methodo", a relação entre intuição e conceito é mais complexa. Também não é possível aqui tratar mais detidamente desse tão difícil tema. Cf. STOLZENBERG, Jürgen (1986) : Fichtes Begriff der intellektuellen Anschauung. Die Entwicklung in den Wissenschaftslehren von 1793/94 bis 1801/02. Stuttgart.

51. Mesmo na seção I do "Ensaio de uma nova exposição da doutrina da ciência" conceitos são mencionados e investigados. Mas não é discutido na seção I o princípio da doutrina da ciência.

52. FICHTE, Johann Gottlieb (1970 b): Zweite Einleitung in die Wissenschaftslehre, in: Gliwitzky, Hans/Lauth, Reinhard (Hgg.): Johann Gottlieb Fichte-Gesamtausgabe der Bayerischen Akademie der Wissenschaften. Bd. I.4. Stuttgart/Bad Cannstatt, p. 217; p. 226-227. Isso, porém, não tem validade quando Fichte tematiza o princípio da doutrina da ciência ou a autoconsciência originária. Nesse contexto, Fichte emprega a expressão 'consciência imediata'. FICHTE 1970, p. 276.

53. Na seção III do "Ensaio de uma nova exposição da doutrina da ciência", Fichte explica que o conceito não é nada mais que uma atividade, só que apreendida "em repouso". A isso ele ainda acrescenta: "em toda parte o conceito não é nada mais que a atividade do próprio intuir, só que apreendida não como agilidade, mas como repouso e determinidade". FICHTE 1970, p. 280. A concepção de Fichte da relação entre intuição e conceito não será investigada no âmbito deste ensaio.

54. Por essa razão, a expressão 'de um objeto' foi posta neste parágrafo entre hífens. A explicação da constituição da consciência intencional deve ainda ser distinguida da explicação epistemológica da constituição da certeza de ser sujeito pensante e epistêmico da consciência. Ela não será tratada neste ensaio.

55. FICHTE 1970, p. 276; p. (182): "A intuição de que se trata aqui é um pôr-se como pondo (algo objetivo, que também pode ser eu mesmo, como mero objeto)".

Diferentemente de Klotz, em Selbstbewußtsein und praktische Identität, eu distingo entre essa intuição e a intuição intelectual. Na "Doutrina da ciência nova methodo", Fichte explica que a intuição intelectual é uma intuição daquela intuição que ele caracteriza com a locução "pôr-se como pondo". FICHTE 1978, p. 30s. Ao contrário, Klotz parece identificar a intuição intelectual com a intuição no sentido da locução "pôr-se como pondo". KLOTZ 2002, p. 106. A explicação da relação entre a intuição e a intuição intelectual é um empreendimento amplo e complexo que extrapola o quadro dessa investigação. Neste ponto, basta a indicação de que a interpretação desenvolvida nesta seção desta investigação vale para a intuição e apenas de modo limitado também para a intuição intelectual, em relação à qual aspectos adicionais têm de ser levados em consideração.

56. FICHTE 1979, p. 341.

57. Em um trecho adiante desse manuscrito Fichte explica que essa consciência de si mesmo não é um caso do pensamento, mas uma intuição. FICHTE 1979, p. 347. 
58. FICHTE 1970, p. 277.

59. É por esse motivo que no título para esta seção designamos a interpretação da concepção de Fichte da estrutura do eu como um interpretação ontológica.

60. Digna de discussão é a pergunta se Fichte, com a locução "como pondo", visa a atividade do pensamento ou (ainda) deixa indeterminado de qual tipo de atividade se trata. No "Ensaio de uma nova exposição da doutrina da ciência", Fichte menciona, antes da introdução da fórmula "pôr-se como pondo (algo objetivo)" a consciência do pensamento e afirma, conforme o conteúdo, que o sujeito se entende como sujeito pensante que tem consciência. FICHTE 1970, p. 276. Por essa razão, eu tendo a interpretar Fichte no sentido de que com a locução "como pondo" não é visada exclusivamente a atividade como tal. Ao contrário, presumo que é visada (também) a atividade do pensamento. Klotz, ao meu ver, compartilha desse ponto de vista. KLOTZ 2002, p. 105. Em todo caso, é uma tarefa central da doutrina da ciência identificar as ações mentais e práticas que caracterizam o sujeito e que não estão limitadas à atividade do pensamento.

61. KLOTZ 2002, p. 109.

62. Em favor desse modo de leitura conta o fato de que Fichte na "Doutrina da ciência nova methodo" caracteriza a intuição com as palavras: "eu me ponho como pondo isto é intuição" (FICHTE 1978, p. 30) e não introduz junto a observação entre parênteses ("algo objetivo, que também pode ser eu mesmo, como mero objeto)". Por isso, a observação entre parênteses parece remeter a um tema que é ignorado ou justamente posto entre parênteses quando se trata do princípio da doutrina da ciência.

63. Como foi mencionado de passagem, na próxima seção o modo de leitura ontológico será completado por um modelo performativo de explicação.

64. FICHTE 1970, p. 280.

65. Klotz também chama a atenção a este ponto. KLOTZ 2002, p. 139-141.

66. Sem dúvida, conceitos determinam os objetos da consciência intencional. Isso, porém, não é problemático, visto que o pôr inclui a atividade do pensamento e essa atividade é reconhecida graças à intuição. A atividade da aplicação de conceitos a objetos é inteiramente reconhecida, mesmo que não seja visto como conceitos surgem por meio do pôr. No entanto, é ao menos questionável se, para Fichte, é visto ou tem de ser visto, em conexão com o pôr, como conceitos se originam.

67. HENRICH 1966, p. 205.

68. Nesta citação, a palavra 'consciência' não significa, portanto, que são aplicados uma intuição sensível e um componente conceitual. Por isso, Fichte a designa também como consciência imediata e, na sequência, como autoconsciência imediata. FICHTE 1970, p. 276.

69. AUSTIN, John Langshaw (2002): Zur Theorie der Sprechakte. Stuttgart, p. 169; p. 179. 70. É controversa essa tese na literatura sobre declarações performativas. Cf. BACH, Kent; HARNISH, Robert Mike (1992): How Performatives Really Work. A Reply to Searle, in: Linguistics and Philosophy 15, p. 97. Isso não é decisivo. Decisivo é o fato de que a significação dessa tese é concebível, mesmo se ela repousasse em uma falsa interpretação das declarações performativas. Em todo caso, também falam a favor da tese reflexões de que a significação linguística é um elemento da ação. Isso vale ao menos para o caso da expressão “eu te amaldiçoo!”. Isso será mais detalhado em breve no texto principal.

71. "Maldição. O desejo de desgraça estilizado e ritualizado contra um outro homem começa a agir, segundo o entendimento bíblico, assim que ele é pronunciado. Essa 
eficácia (aparentemente mágica, mas que deve ser entendida a partir de Deus) da maldição assim como da bênção repousa no poder da palavra falada, que atinge seu objetivo irresistivelmente e atua por gerações adentro." WERLITZ, Jürgen (Hg.) (2018): Die Bibel. Tradução unificada. Edição comentada. Léxico e registro temático. Com definições, chaves temáticas, tabelas temporais, mapas. Volume 4. Stuttgart, p. 110. 72. KANT, Immanuel (1995): Prolegomena zu einer jeden künftigen Metaphysik, die als Wissenschaft wird auftreten können. Edição crítica de Rudolf Malter com adendos. Stuttgart, p. 137. Em uma nota de rodapé, Kant dá o seguinte exemplo: “assim há uma analogia entre a relação jurídica das ações humanas e a relação mecânica das forças motrizes: eu não posso nunca fazer algo contra um outro sem dar-lhe o direito de fazer justamente o mesmo contra mim sob as mesmas condições; assim como nenhum corpo pode atuar sobre o outro com sua força motriz sem causar, através disso, que o outro atue contra ele da mesma maneira. Aqui, direito e força motriz são coisas inteiramente dissemelhantes, mas há completa semelhança em sua relação.” KANT, 1995, p. 137. Nesse exemplo, são tomados em consideração por Kant elementos selecionados de duas relações e outros ignorados. Ações, por exemplo, têm razões e motivos que não desempenham nenhum papel na relação mecânica indicada por Kant. Kant ignora essa diferença. Nessa medida, mesmo a analogia de Kant não é completa ou perfeita. Por isso, vale a ideia de que: perfeição da semelhança existe em relação a uma escolha dos elementos.

\section{RESUMOS}

The aim of this paper is to expose henrich's interpretation of the fichtean insight in the text essay of a new exposition of the doctrine of science and his criticism of fichte. In view of the fact that Dieter Henrich's article Fichte's Original Insight is considered among the most significant and most influential investigations of human subjectivity that have been published in recent decades, it is necessary to present an alternative interpretation of Fichte's position, proving that Henrich's criticism of Fichte can be rejected as unfounded. My proposed alternative reading is grounded in the reflections of Christian Klotz, with which he demonstrates the problem and an alternative way of reading the Fichtean essay, but which will be complemented by means of a performative model of explanation. The result will show, that Henrich's critique of Fichte can be rejected as unjustified according to the guideline of this alternative interpretation.

\section{ÍNDICE}

Keywords: Dieter Henrich, Alternative, Critic, Christian Klotz, Fichte

\section{AUTOR \\ STEFAN LANG}

Martin-Luther-Universität Halle-Wittenberg 